\title{
Occupation and bladder cancer in Boston, USA, Manchester, UK, and Nagoya, Japan
}

\begin{abstract}
ALAN S MORRISON, ${ }^{1}$ ANDERS AHLBOM, ${ }^{2}$ WENDY G VERHOEK, ${ }^{34}$ KUNIO AOKI,${ }^{5}$ IAN LECK, ${ }^{3}$ YOSHIYUKI OHNO, ${ }^{5}$ AND KOJI OBATA ${ }^{6}$

From the Department of Epidemiology, ${ }^{1}$ Harvard University, School of Public Health, Boston, MA 02115, USA; Department of Social Medicine, ${ }^{2}$ Huddinge University Hospital, Karolinska Institute, Sweden; Departments of Community Medicine and Oncology, ${ }^{3}$ University of Manchester, Manchester, England; Department of Epidemiology and Social Research, ${ }^{4}$ University Hospital of South Manchester, Manchester, England; Department of Preventive Medicine, ${ }^{5}$ Nagoya University School of Medicine, Nagoya, Japan; and Department of Urology, ${ }^{6}$ First Red Cross Hospital, Nagoya, Japan
\end{abstract}

SUMMARY Relations between occupational history and the development of cancer of the lower urinary tract ("bladder cancer") were evaluated in Boston, Massachusetts, USA, Manchester, UK, and Nagoya, Japan. Population-based series of incident cases and controls were identified and interviewed in each area. The present analysis was limited to men and was based on 430 cases and 397 controls in Boston, 399 cases and 493 controls in Manchester, and 226 cases and 443 controls in Nagoya. In Boston, elevated risk of bladder cancer was associated with employment related to dyes (relative risk $=2 \cdot 1 ; 90 \%$ confidence interval, $0 \cdot 9-5 \cdot 1)$, leather $(1 \cdot 7 ; 1 \cdot 1-2 \cdot 6)$, paint $(1 \cdot 5$; $0 \cdot 9-2 \cdot 4)$, or organic chemicals $(1 \cdot 6 ; 1 \cdot 1-2 \cdot 5)$. In Manchester, elevated risk was associated with work related to leather $(3 \cdot 2 ; 1 \cdot 3-8 \cdot 0)$ or health care $(1 \cdot 8 ; 0 \cdot 9-3 \cdot 6)$. No clear association was observed between occupation and risk in Nagoya. Elevations in risk related to occupation generally were stronger in men under 65 years of age compared to older men. Differences from place to place in associations between occupation and risk may be the result of differences in the exposures to hazardous agents that jobs with the same title involve.

The investigation of occupational hazards has played a central role in research on the causes of bladder cancer. Carcinogens used in the workplace have been identified, and risk of bladder cancer has been linked to additional occupations in which carcinogens have not yet been found. We have done a collaborative study of environmental risk factors for bladder cancer in the US, UK, and Japan, and we have previously described our results on artificial sweeteners, coffee drinking, and smoking. ${ }^{1-4}$ In the present report we analyse the relations of occupational history to the development of bladder cancer in these three areas.

\section{Methods}

Case-control studies were carried out in Greater Boston, Massachusetts, USA, part of Greater

*Present address: Department of Community Health, Brown University, Box G, Providence, RI 02912, USA.
Manchester County, UK, and metropolitan Nagoya, Japan. The study methods have been described in detail. ${ }^{12}$ Briefly, an attempt was made to assemble a complete series of incident cases in each area during the respective study period (March 1976 through May 1977 in Boston; October 1976 through September 1978 in Manchester; January 1976 through December 1978 in Nagoya). Case identification was accomplished primarily through hospitals. To be eligible a case had to have had an initial diagnosis of a primary neoplasm of the lower urinary tract (bladder, ureter, renal pelvis, urethra) during the study period and to be 21-89 years old and a resident of the study area at the time of diagnosis. Tumours throughout the histological spectrum from papilloma to invasive neoplasia were included. There were 741 cases identified in Boston, 577 in Manchester, and 348 in Nagoya. Ninety-five per cent of the tumours occurred in the bladder. A centralised pathology review indicated that virtually every case had a transitional or squamous cell tumour. ${ }^{5}$ For 
brevity, the term "bladder cancer" is used as a synonym for neoplasms of the lower urinary tract. ${ }^{1}$

Controls were selected from electoral registers available in each study area. The sampling methods ensured that the control series would have an age and sex distribution similar to that of the respective series of cases. There were 677 controls selected in Boston, 817 in Manchester, and 735 in Nagoya.

Subjects were interviewed according to a standardised schedule. If a subject was too ill for interview, could not be contacted, or had died, an attempt was made to interview a proxy-a relative or friend familiar with the subject's background and habits. In Boston and Manchester, most interviews were done at subjects' homes. In Nagoya, most controls were interviewed at home, but the majority of cases were interviewed as inpatients or during outpatient visits. ${ }^{2}$ Interviews were obtained for 597 cases ( $81 \%$ of the total eligible) and 544 controls $(80 \%)$ in Boston, 555 cases $(96 \%)$ and 735 controls $(90 \%)$ in Manchester, and 293 cases $(84 \%)$ and 589 controls $(80 \%)$ in Nagoya. The present analysis was limited to men for whom smoking history was known. There were 430 such cases and 397 such controls in Boston, 399 cases and 493 controls in Manchester, and 226 cases and 443 controls in Nagoya.

All subjects were asked whether or not they had ever held jobs in any of 15 groups of occupations*. For each category in which they had worked, subjects were asked about all jobs that they had.held with the corresponding employers. The questions on each job included the title and the dates on which the job began and ended. Job titles were coded according to a system described elsewhere. ${ }^{6}$ In order to assess the relation between possible exposure to hazardous substances and risk, occupational titles for men who had worked in each broad category were subdivided into "processing" $v$ "service" jobs. Processing jobs were those that involved the activities or substances that are characteristic of the occupation category. For example, jobs "in dye manufacturing or in cloth or leather dyeing" were classified as "processing" jobs if they involved production processes such as mixing, blending, distilling, etc in the manufacture of dyes, the mixing of finished dyes, or processes such as saturating, coating, and spraying in the application of finished dyes to cloth or leather. Other jobs such as

\footnotetext{
"In this paper these groups are given the following titles: dye (dye manufacturing, or cloth or leather dyeing); textiles (textiles industry, or manufacture of cloth or cloth garments); rubber (rubber industry, or manufacture of rubber products); leather (leather or tanning industry, manufacture of leather products, or shoemaking); paint (painting, or paint manufacture); clerk (clerk, secretary, typist or receptionist); cook (cook, or food processing); health (health services); barber (barber or hairdresser); organic chemicals (organic chemicals or petroleum or plastics industry, or work with organic chemicals or petroleum products); construction, etc (plumber, work with metals, building construction industry, or manufacture or use of electric cable); carpenter (carpenter, or wood or wor prest fitter (gas fitter, or work with coal gas or natural gas); coal, coke (work with coal or coke); asphalt (work with asphalt, or pitch).
}

administrator, clerk, truck driver, and shipper were designated as the "service" group. Men were considered to have been "processing" workers if they had held processing jobs for at least five years. Otherwise they were considered to have been "service" workers.

The magnitude of the effect of occupational exposure on the occurrence of bladder cancer was measured by the " relative risk"-the ratio of the incidence rate of bladder cancer in men with a given employment history to the rate in unexposed men, defined as those who had never been employed in the broad occupation category under consideration. Also the $90 \%$ confidence intervals were calculated where the lower bounds are equivalent to $95 \%$ one sided confidence bounds. Relative risks were estimated by fitting multivariate logistic regression models to the data. ${ }^{7}$ The effects of age and cigarette smoking were controlled by use of indicator variables for three age strata $(<65,65-74$, and $\geqslant 75$ years) and three smoking strata (non-smokers, smokers of less than a pack a day and ex-smokers, and smokers of a pack a day or more). Indicator variables were also used for the two separate groups of jobs, processing and service, allowing for comparison of the relative risk between these two groups. Interaction terms were used to analyse the possibility of modification by age on the effect of the exposure on the disease. Relative risk estimates are not given for occupation categories that contained five or less subjects.

\section{Results}

Table 1 gives the numbers of exposed subjects in the case and control series and the total numbers of cases and controls. In table 2 are displayed the relative risks associated with employment (as either a processing or service worker) in each of the 15 occupation categories. Although not presented here, a crude analysis without control of smoking and age gave virtually the same results. Dye was associated with an elevated risk in Boston but not at all in Manchester and only slightly in Nagoya. Leather was associated with risk in both Boston and Manchester, albeit to a lesser degree in Boston. A small increase in risk related to painting also was noted in Boston. Health occupations were positively associated with risk in Manchester. Organic chemicals were linked to a modest increase in risk in Boston but only to slight increases in Manchester and Nagoya. An overall relative risk greater than 1.4 was not observed for any other occupation category in any centre.

Tables 3 to 7 show the relative risks associated with processing and service jobs, by age, for five of the occupation categories most strongly suspected of being linked to bladder cancer. For dye workers, the 
Table 1 Numbers of cases and controls, by occupation category and area

\begin{tabular}{|c|c|c|c|c|c|c|}
\hline \multirow[b]{2}{*}{ Occupation category* } & \multicolumn{2}{|l|}{ Boston } & \multicolumn{2}{|c|}{ Manchester } & \multicolumn{2}{|c|}{ Nagoya } \\
\hline & Cases & Controls & Cases & Controls & Cases & Controls \\
\hline Dye & 13 & 5 & 24 & 35 & 6 & 8 \\
\hline Textiles & 30 & 30 & 79 & 101 & 16 & 31 \\
\hline Rubber & 21 & 17 & 22 & 27 & 2 & 2 \\
\hline Leather & 45 & 26 & 11 & 5 & 2 & 4 \\
\hline Paint & 35 & 21 & 23 & 37 & 5 & 13 \\
\hline Clerk & 47 & 35 & 75 & 83 & 13 & 37 \\
\hline Cook & 38 & 30 & 34 & 39 & 8 & 15 \\
\hline Health & 7 & 8 & 13 & 10 & 2 & 7 \\
\hline Barber & 7 & 6 & 2 & 2 & 1 & 2 \\
\hline Organic chemicals & 50 & 28 & 48 & 50 & 12 & 20 \\
\hline Construction, etc & 139 & 116 & 199 & 262 & 17 & 27 \\
\hline Carpenter & 40 & 37 & 29 & 46 & 19 & 44 \\
\hline Gas fitter & 14 & 8 & 15 & 22 & 0 & 1 \\
\hline Coal, coke & 23 & 18 & 42 & 57 & 14 & 21 \\
\hline Asphalt & 23 & 18 & 19 & 26 & 3 & 1 \\
\hline Total number ${ }^{+}$ & 430 & 397 & 399 & 493 & 226 & 443 \\
\hline
\end{tabular}

"Subjects may be included in more than one occupation category.

tIncludes subjects not assigned to any specified occupation category.

Table 2 Relative risk $(R R)^{*}$ with $90 \%$ confidence interval $(C I)$, by occupation category and area

\begin{tabular}{|c|c|c|c|c|c|c|}
\hline \multirow[b]{2}{*}{ Occupation category } & \multicolumn{2}{|c|}{ Boston } & \multicolumn{2}{|c|}{ Manchester } & \multicolumn{2}{|c|}{ Nagoya } \\
\hline & $R R$ & $90 \% \mathrm{CI}$ & $R R$ & $90 \% \mathrm{CI}$ & $R R$ & $90 \% \mathrm{CI}$ \\
\hline Dye & $2 \cdot 1$ & $0.9-5.1$ & 0.8 & $0 \cdot 5-1 \cdot 2$ & $1 \cdot 3$ & $0 \cdot 5-3 \cdot 3$ \\
\hline Textiles & 0.9 & $0.6-1.4$ & 0.9 & $0 \cdot 7-1 \cdot 2$ & $1 \cdot 0$ & $0.6-1.6$ \\
\hline Rubber & $1 \cdot 2$ & $0 \cdot 7-2 \cdot 0$ & $1 \cdot 1$ & $0.6-1.7$ & - & \\
\hline Leather & $1 \cdot 7$ & $1 \cdot 1-2 \cdot 6$ & $3 \cdot 2$ & $1 \cdot 3-8 \cdot 0$ & $1 \cdot 0$ & $0 \cdot 2-4 \cdot 2$ \\
\hline Paint & $1 \cdot 5$ & $0.9-2.4$ & 0.7 & $0.5-1 \cdot 2$ & 0.7 & $0 \cdot 3-1 \cdot 7$ \\
\hline Clerk & $1 \cdot 2$ & $0 \cdot 8-1 \cdot 8$ & $1 \cdot 2$ & $0.9-1 \cdot 7$ & 0.6 & $0 \cdot 4-1 \cdot 1$ \\
\hline Cook & $1 \cdot 2$ & $0.8-1.9$ & 1.0 & $0 \cdot 7-1 \cdot 5$ & $1 \cdot 0$ & $0 \cdot 5-2 \cdot 1$ \\
\hline Health & 0.7 & $0 \cdot 3-1 \cdot 8$ & $1 \cdot 8$ & $0.9-3.6$ & 0.5 & $0 \cdot 1-2 \cdot 0$ \\
\hline Barber & $1 \cdot 0$ & $0.4-2.6$ & - & & - & \\
\hline Organic chemicals & 1.6 & $1 \cdot 1-2 \cdot 5$ & $1 \cdot 3$ & $0.9-1.9$ & $1 \cdot 2$ & $0 \cdot 6-2 \cdot 1$ \\
\hline Construction, etc & $1 \cdot 1$ & $0.9-1.5$ & 0.9 & $0 \cdot 7-1 \cdot 1$ & $1 \cdot 2$ & $0.7-2 \cdot 0$ \\
\hline Carpenter & 0.9 & $0.6-1.4$ & 0.7 & $0 \cdot 5-1 \cdot 1$ & 0.8 & $0.5-1.4$ \\
\hline Gas fitter & 1.4 & $0 \cdot 7-3 \cdot 0$ & 0.9 & $0 \cdot 5-1 \cdot 5$ & - & \\
\hline Coal, coke & $1 \cdot 1$ & $0.6-1.8$ & 0.8 & $0.6-1.2$ & $1 \cdot 3$ & $0 \cdot 7-2 \cdot 3$ \\
\hline Asphalt & $1 \cdot 1$ & $0.6-1.8$ & $1 \cdot 0$ & $0.6-1.7$ & - & \\
\hline
\end{tabular}

*Age and smoking history controlled (tables 2-8).

$-=$ number of exposed less than or equal to 5 (tables 2-8).

Table 3 Numbers of cases and controls and relative risk $(R R)$ associated with process and service jobs in dye occupations, by age and area

\begin{tabular}{|c|c|c|c|c|c|c|c|c|c|}
\hline \multirow[b]{2}{*}{ Group } & \multicolumn{3}{|l|}{ Boston } & \multicolumn{3}{|c|}{ Manchester } & \multicolumn{3}{|c|}{ Nagoya } \\
\hline & Cases & Controls & $R R$ & Cases & Controls & $R R$ & Cases & Controls & $R R$ \\
\hline \multicolumn{10}{|l|}{ Age $<65$ yr } \\
\hline Process & 0 & 0 & - & 1 & 5 & 0.2 & 0 & 2 & - \\
\hline Service & 6 & 1 & $5 \cdot 2$ & 11 & 12 & $1 \cdot 0$ & 3 & 0 & - \\
\hline Total & 6 & 1 & $5 \cdot 2$ & 12 & 17 & $0 \cdot 8$ & 3 & 2 & - \\
\hline \multicolumn{10}{|l|}{ Age $\geq 65$ yr } \\
\hline Process & 3 & 0 & - & 5 & 6 & $1 \cdot 0$ & 1 & 3 & - \\
\hline Service & 4 & 4 & $0 \cdot 7$ & 7 & 12 & 0.7 & 2 & 3 & - \\
\hline Total & 7 & 4 & $1 \cdot 4$ & 12 & 18 & $0 \cdot 8$ & 3 & 6 & 0.9 \\
\hline
\end{tabular}


series from Boston shows a considerably higher relative risk for those under the age of 65 as compared to those at higher ages (table 3). The numbers of process workers were too small to reveal useful information about the association between extent of exposure to dyes and disease risk. In both Boston and Manchester, the overall relative risks associated with rubber were close to 1 (table 2). For the younger age group in Boston, however, the relative risk exceeded 2 , while that in the older age group was close to 1 (table 4 ). The numbers of process workers under 65 years were too small to allow for estimation of the relative risk in that group. In Manchester the relative risks were close to unity in both age groups. The relative risk associated with occupational exposure to leather was substantially higher in the younger age group than in the older in both the Boston and the Manchester series (table 5). In both age groups in Boston, the relative risk estimates for processing and service workers were similar, while the data were too sparse in Manchester to allow for estimation of relative risks for the two

Table 4 Numbers of cases and controls and relative risk $(R R)$ associated with process and service jobs in rubber occupations, by age and area

\begin{tabular}{|c|c|c|c|c|c|c|c|c|c|}
\hline \multirow[b]{2}{*}{ Group } & \multicolumn{3}{|c|}{ Boston } & \multicolumn{3}{|c|}{ Manchester } & \multicolumn{3}{|c|}{ Nagoya } \\
\hline & Cases & Controls & $R R$ & Cases & Controls & $R R$ & Cases & Controls & $\boldsymbol{R} R$ \\
\hline \multicolumn{10}{|l|}{ Age $<65$ yr } \\
\hline Process & 3 & 1 & - & 4 & 7 & 0.7 & 0 & 0 & - \\
\hline Service & 5 & 2 & $2 \cdot 5$ & 6 & 4 & $2 \cdot 4$ & 1 & 1 & - \\
\hline Total & 8 & 3 & $2 \cdot 6$ & 10 & 11 & $1 \cdot 2$ & 1 & 1 & - \\
\hline \multicolumn{10}{|l|}{ Age $\geqslant 65 \mathrm{yr}$} \\
\hline Process & 4 & 4 & 0.9 & 9 & 5 & $2 \cdot 2$ & 0 & 1 & - \\
\hline Service & 9 & 10 & 0.8 & 3 & 11 & 0.3 & 1 & 0 & - \\
\hline Total & 13 & 14 & 0.9 & 12 & 16 & 0.9 & 1 & 1 & - \\
\hline
\end{tabular}

Table 5 Numbers of cases and controls and relative risk $(R R)$ associated with process and service jobs in leather occupations, by age and area

\begin{tabular}{|c|c|c|c|c|c|c|c|c|c|}
\hline \multirow[b]{2}{*}{ Group } & \multicolumn{3}{|c|}{ Boston } & \multicolumn{3}{|c|}{ Manchester } & \multicolumn{3}{|c|}{ Nagoya } \\
\hline & Cases & Controls & $R R$ & Cases & Controls & $R R$ & Cases & Controls & $R R$ \\
\hline \multicolumn{10}{|l|}{ Age $<65 \mathrm{yr}$} \\
\hline Process & 6 & 3 & $2 \cdot 1$ & 1 & 2 & - & 2 & 1 & - \\
\hline Service & 11 & 4 & $2 \cdot 6$ & 6 & 0 & $x$ & 0 & 0 & - \\
\hline Total & 17 & 7 & $2 \cdot 4$ & 7 & 2 & $5 \cdot 3$ & 2 & 1 & - \\
\hline \multicolumn{10}{|l|}{ Age $\geqslant 65 \mathrm{yr}$} \\
\hline Process & 15 & 11 & 1.4 & 0 & 2 & - & 0 & 1 & - \\
\hline Service & 13 & 8 & 1.5 & 4 & 1 & - & 0 & 2 & - \\
\hline Total & 28 & 19 & 1.4 & 4 & 3 & 1.8 & 0 & 3 & - \\
\hline
\end{tabular}

Table 6 Numbers of cases and controls and relative risk $(R R)$ associated with process and service jobs in paint occupations, by age and area

\begin{tabular}{|c|c|c|c|c|c|c|c|c|c|}
\hline \multirow[b]{2}{*}{ Group } & \multicolumn{3}{|l|}{ Boston } & \multicolumn{3}{|c|}{ Manchester } & \multicolumn{3}{|c|}{ Nagoya } \\
\hline & Cases & Controls & $R R$ & Cases & Controls & $R R$ & Cases & Controls & $R R$ \\
\hline \multicolumn{10}{|l|}{ Age $<65$ yr } \\
\hline Process & 7 & 1 & $7 \cdot 1$ & 1 & 7 & 0.2 & 0 & 2 & - \\
\hline Service & 14 & 9 & 1.5 & 10 & 12 & $1 \cdot 1$ & 1 & 2 & - \\
\hline Total & 21 & 10 & $2 \cdot 1$ & 11 & 19 & 0.7 & 1 & 4 & - \\
\hline \multicolumn{10}{|l|}{ Age $\geqslant 65 \mathrm{yr}$} \\
\hline Process & 6 & 8 & 0.6 & 6 & 3 & $2 \cdot 1$ & 3 & 2 & - \\
\hline Service & 8 & 3 & $2 \cdot 4$ & 6 & 15 & 0.4 & 1 & 7 & $0 \cdot 3$ \\
\hline Total & 14 & 11 & 1.0 & 12 & 18 & 0.7 & 4 & 9 & 0.8 \\
\hline
\end{tabular}


types of workers separately. Table 2 showed a somewhat elevated risk associated with paint jobs in Boston but not in the other two centres. When analysed by age and type of job, it was found that the excess risk in Boston was due entirely to the younger age group, in which the risk was substantially higher among process compared to service workers (table 6). For workers with organic chemicals, relative risks of about 2 were seen in the younger age group in all three centres, while in the older age group the relative risk was close to unity (table 7 ). No substantial differences between processing and service workers were noted. A sixth occupation of some interest is barbering or hairdressing. The only study group that contained more than five exposed subjects was Boston men aged 65 or older, in which six cases and three controls were exposed (relative risk $=1 \cdot 6,90 \%$ confidence interval $0 \cdot 5-5 \cdot 3$ ).

To determine whether the relative risk associated with a given occupation reflected employment in other ones, histories of employment in the above six occupations (dye, rubber, leather, paint, barber, organic chemicals) were added to the analytical model, together with age and smoking history. The results are shown in table 8 . As can be seen from a comparison with table 2 , no important changes in the relative risk estimates took place.

\section{Discussion}

About a decade before the present study, Cole et al did a case-control study of bladder cancer in the Boston area. ${ }^{8}$ As in the present study, Cole et al identified cases and sampled controls on a population-wide basis and obtained occupation histories by personal interview. They found elevated risks associated with five previously suspected occupation categories: dyestuffs (relative risk $=2 \cdot 2)$, rubber and rubber products $(1 \cdot 6)$, leather and leather products $(2 \cdot 0)$, paint $(1 \cdot 2),{ }^{*}$ and other organic chemicals (1.4). Only a few other occupations were associated with risk of bladder cancer in either the Cole study or our own. Both studies also found generally higher relative risks associated with the occupations listed in men under 65 years of age compared to older men. Thus the two sets of results are remarkably similar. Associations between bladder cancer and the listed occupations have been found in several other studies in the United States and Canada. However, we observed ${ }^{\varnothing}$ little or no elevation in risk in Boston related to? employment in medical occupations, food processing, welding, metal machining, and clerical

*The relative risk for painters was 1.4 in an occupational title analysis.

Table 7 Numbers of cases and controls and relative risk $(R R)$ associated with process and service jobs in organic chemicals occupations, by age and area

\begin{tabular}{|c|c|c|c|c|c|c|c|c|c|}
\hline \multirow[b]{2}{*}{ Group } & \multicolumn{3}{|l|}{ Boston } & \multicolumn{3}{|c|}{ Manchester } & \multicolumn{3}{|c|}{ Nagoya } \\
\hline & Cases & Controls & $R R$ & Cases & Controls & $R R$ & Cases & Controls & $R R$ \\
\hline \multicolumn{10}{|c|}{ Age $<65$ yr } \\
\hline Process & 5 & 2 & $2 \cdot 6$ & 12 & 11 & 1.7 & 4 & 4 & 1.9 \\
\hline Service & 28 & 13 & $2 \cdot 0$ & 19 & 14 & $2 \cdot 1$ & 4 & 5 & $1 \cdot 7$ \\
\hline Total & 33 & 15 & $2 \cdot 0$ & 31 & 25 & 1.9 & 8 & 9 & $1 \cdot 8$ \\
\hline \multicolumn{10}{|c|}{ Age $\geq 65 \mathrm{yr}$} \\
\hline Process & 4 & 5 & 0.7 & 7 & 14 & 0.6 & 3 & 4 & $1 \cdot 4$ \\
\hline Service & 13 & 8 & $1 \cdot 4$ & 10 & 11 & 1.0 & 1 & 7 & 0.3 \\
\hline Total & 17 & 13 & $1 \cdot 2$ & 17 & 25 & 0.7 & 4 & 11 & 0.7 \\
\hline
\end{tabular}

Table 8 Relative risk (RR) and 90\% confidence interval (CI) associated with selected occupation categories, estimated with simultaneous control for the other occupations as well as age and smoking

\begin{tabular}{|c|c|c|c|c|c|c|}
\hline \multirow[b]{2}{*}{ Occupation category } & \multicolumn{2}{|c|}{ Boston } & \multicolumn{2}{|c|}{ Manchester } & \multicolumn{2}{|c|}{ Nagoya } \\
\hline & $R R$ & $90 \% C I$ & $\boldsymbol{R} R$ & $90 \% C I$ & $R R$ & $90 \% \mathrm{CI}$ \\
\hline Dye & $1 \cdot 7$ & $0 \cdot 7-4 \cdot 3$ & 0.8 & $0 \cdot 5-1 \cdot 2$ & $1 \cdot 3$ & $0.5-3 \cdot 3$ \\
\hline Rubber & $1 \cdot 0$ & $0.6-1.8$ & $1 \cdot 0$ & $0.6-1 \cdot 6$ & - & \\
\hline Leather & $1 \cdot 7$ & $1 \cdot 1-2 \cdot 6$ & 3.6 & $1.4-9.0$ & $1 \cdot 0$ & $0 \cdot 2-4 \cdot 1$ \\
\hline Paint & $1 \cdot 5$ & $0.9-2.4$ & 0.7 & $0.4-1 \cdot 1$ & 0.7 & $0 \cdot 3-1 \cdot 6$ \\
\hline Barber & $1 \cdot 1$ & $0.4-2.8$ & - & & - & \\
\hline Organic chemicals & $1 \cdot 6$ & $1 \cdot 1-2 \cdot 5$ & $1 \cdot 4$ & $1 \cdot 0-2 \cdot 0$ & $1 \cdot 2$ & $0 \cdot 6-2 \cdot 2$ \\
\hline
\end{tabular}


work, which are additional associations that have been observed by others. ${ }^{8-13}$

Studies in England have related bladder cancer to work with rubber and electrical cable, textiles, and to medical occupations, besides the very strong and well-known association with dyestuffs. ${ }^{14-18}$ The latter association has been found in Manchester. ${ }^{19}$ In contrast to previous studies, we found no evidence of risk among dye workers, rubber workers, or textile workers in the series from Manchester. Health workers had a modest elevation of risk, and risk also was elevated for men under age 65 whose work had involved organic chemicals. The largest overall elevation in risk in the Manchester series was that observed for leather workers.

Of the occupations that we studied, none was strongly associated with risk in Nagoya, although compared to Boston and Manchester, only small proportions of subjects had been exposed in most categories. Relatively little previous investigation of occupation and bladder cancer has been done in Japan. The disease has been linked to aromatic amine exposures. ${ }^{20-22}$ A case-control study in Nagoya suggested elevated risk in dye-workers, painters, and workers with ceramics, glass, and iron (Obata et al, unpublished).

To us, the most striking finding of the present analysis is the lack of consistent results among the three study areas. The expected pattern of results was observed only in Boston, and leather working was the only occupational category clearly associated with risk of bladder cancer in even two of the three study areas. Some preliminary analyses (not shown) suggested that differences in findings among the areas studied were not the result of different durations of employment in jobs involving possibly hazardous substances. Further, we do not believe that these inconsistencies stem from fundamental differences in study methods. As far as possible we standardised the procedures to identify and interview subjects, and our findings on the use of artificial sweeteners, coffee drinking, and especially smoking, a well-documented cause of bladder cancer, were essentially the same in the three areas. ${ }^{1-4}$

Although we are able to offer explanations that are only tentative, we believe that the area-to-area differences that we have found are a consequence of the nature of occupation as an epidemiological variable. An occupational title is not an exposure but is merely an index of exposures that probably were inadvertent. These exposures may be numerous and highly intercorrelated. Their characteristics differ from time to time and from place to place, even for jobs with the same title. Because of trade practices, it may not be possible to identify all the chemical and physical agents that a given job involves. Even within a given setting the same job title may apply to people who are not exposed, lightly exposed, or heavily exposed to a given agent or group of agents. The similarity of our findings to those of Cole et al may stem from the fact that the characteristics of hazardous occupations in Boston did not change much over the period covered by the two studies. On the other hand, the uncertain connections between job titles and the corresponding exposures may make it unlikely that strong associations will be consistently observed in studies widely separated in time or place. Many of the inconsistent findings among the three centres in our study, and between previous studies and the present one, might be explained on this basis. Further, some discrepancies would be explained as a result of chance variability.

One inconsistency in our findings is worth special note-the association between dye-working and bladder cancer that was seen in Boston but not in Manchester. This difference may reflect the epidemiological history of occupational bladder cancer. The most important initial work in this field was done in the UK, and the results of this work are likely to have led to pertinent changes in industrial practices earlier in the UK than in the US. ${ }^{23-25}$

There are two positive findings that deserve further attention. First, an association between occupations in the leather industry and bladder cancer has been found in several studies in different areas. $^{8112627}$ The consistency of the association and its specificity suggest that some workers in this industry have been exposed to one or more carcinogens. To date, however, a clear link between a carcinogen in the industry and risk has not been found. Thus, it is not known whether there is a continuing hazard in this industry. Second, the present study generally found the relative risks associated with occupation category to be higher in comparatively young men, as did the earlier study in Boston. ${ }^{68}$ One plausible explanation of this result is that the effect of an occupational exposure is constant on an absolute scale and therefore becomes diluted or even undetectable in the higher age group where the baseline incidence rate is higher. It is also possible, however, that occupational hazards have their greatest effects among relatively young men.

This study was supported by Public Health Service grant R26CA-18660 from the National Cancer Institute through the National Bladder Cancer Project, by a research grant from the North Western Regional Health Authority, England, by a grant from the Swedish Medical Research Council (project no. G216), by grants from Du Pont and Conoco to Harvard University, and by a grant (FRA-208) from 
the American Cancer Society. We appreciate the contributions of people listed in previous publications. ${ }^{1-4}$

\section{References}

${ }^{1}$ Morrison AS, Buring JE. Artificial sweeteners and cancer of the lower urinary tract. $N$ Engl J Med 1980; 302: $537-41$.

${ }^{2}$ Morrison AS, Buring JE, Verhoek WG, et al. Coffee drinking and cancer of the lower urinary tract. JNCI 1982; 68: 91-4.

${ }^{3}$ Morrison AS, Verhoek WG, Aoki K, et al. Artificial sweeteners and bladder cancer in Manchester, UK, and Nagoya, Japan. Br J Cancer 1982; 45: 332-7.

${ }^{4}$ Morrison AS, Buring JE, Verhoek WG, et al. An international study of smoking and bladder cancer. $J$ Urol, 1984; 131: 650-4.

${ }^{5}$ Morrison AS, Proppe KH, Verhoek WG, et al. Histologic features of bladder cancer in Boston, USA, Manchester, UK, and Nagoya, Japan. Int J Cancer 1982; 30: 701-5.

${ }^{6}$ Hoar SK, Morrison AS, Cole P, et al. An occupation and exposure linkage system for the study of occupational carcinogenesis. J Occup Med 1980; 22: 722-6.

${ }^{7}$ Breslow NE, Day NE. Statistical methods in cancer research. Vol I. The analysis of case-control studies. Lyon: International Agency for Research on Cancer, 1980.

${ }^{8}$ Cole P, Hoover R, Friedell G. Occupation and cancer of the lower urinary tract. Cancer 1972; 29: 1250-60.

${ }^{9}$ Wynder EL, Goldsmith R. The epidemiology of bladder cancer. A second look. Cancer 1977; 40: 1246-68.

${ }^{10}$ Howe GR, Burch JD, Miller AB, et al. Tobacco use, occupation, coffee, various nutrients, and bladder cancer. 1980; JNCI 64: 701-13.

${ }^{11}$ Decoufle P: Cancer risks associated with employment in the leather and leather products industry. Arch Environ Health 1979; 34: 33-7.

${ }^{12}$ Silverman DT, Hoover RN, Albert S, et al. Occupation and cancer of the lower urinary tract in Detroit. $J N C I$ 1983; 70: $237-45$.
${ }^{13}$ Williams RR, Stegens NL, Goldsmith JR. Associations of cancer site and type with occupation and industry from the Third National Cancer Survey interview. JNCI 1977; 59: 1147-85.

${ }^{14}$ Anthony HM, Thomas GM. Tumors of the urinary bladder: an analysis of the occupation of 1,030 patients in Leeds, England. JNCI 1970, 45: 879-95.

${ }^{15}$ Case RAM, Hosker ME. Tumour of the urinary bladder as an occupational disease in the rubber industry in England and Wales. Br J Prev Soc Med 1954; 8: 39-50.

${ }^{16}$ Veys CA. Two epidemiological inquiries into the incidence of bladder tumors in industrial workers. JNCI 1969; 43: 219-26.

${ }^{17}$ Davies JM: Bladder tumours in the electric-cable industry. Lancet 1965; 2: 143-6.

${ }^{18}$ Case RAM, Hosker MF, McDonald DB, et al. Tumours of the urinary bladder in workmen engaged in the manufacture and use of certain dyestuff intermediates in the British chemical industry. Part $I$. The role of aniline benzidine, alpha-naphthylamine, and beta-naphthylamine. Br J Ind Med 1954; 11: 75-104.

${ }^{19} \mathrm{Scott}$ TS. The incidence of bladder tumours in a dyestuffs factory. $\mathrm{Br} J$ Ind Med 1952; 9: 127-32.

${ }^{20}$ Hueper WC. Occupational and environmental cancers of the urinary tract. New Haven: Yale University Press, 1969, 136-8.

${ }^{21}$ Tsuji I, Kuroda K, Nakajima, et al. Mortality and clinical statistics of bladder tumors in Japan, with occupational bladder tumors. Jap J Cancer Clin 7: 347-55.

${ }^{22}$ Nishimura I. Bladder cancer caused by Anilin dye. J Jap Soc Urol 1940; 29: 733.

${ }^{23}$ Case RAM. Tumours of the urinary tract as an occupational disease in several industries. Ann $R$ Coll Surg Eng 1966; 39: 213-35.

${ }^{24}$ Williams MHG. Occupational tumors of the bladder. In Raven RW, ed. Cancer, Vol 3. London: Butterworth, 1958, 337-80.

${ }^{25}$ Breslow L, ed. A history of cancer control in the United States 1946-1971. Book One. A history of scientific and technical advances in cancer control. DHEW Publication No. (NIH) 78-1517, 131-55.

${ }^{26}$ Lockwood $K$. On the etiology of bladder tumors in Kobenhavn-Frederiksberg: an inquiry of 369 patients and 369 controls. Acta Path Microbiol Scand 1961; 51 (Suppl 145): 1-66.

${ }^{27}$ Wynder EL, Onderdonk J, Mantel N. An epidemiological investigation of cancer of the bladder. Cancer 1963; 16: 1388-1407. 